\title{
UNA EXPERIÈNCIA D'ENSENYAMENT DEL TEMPS HISTÒRIC
}

\author{
Antoni Santisteban Fernández. Àrea de Didàctica de les Ciències Socials. URV
}

En aquest article es presenta una experiència d'ensenyament del temps històric a l'escola primària. Què és el temps històric? Com s'ensenya? Com s'aprèn? Sense una comprensió del temps històric els nens i nenes no poden apropar-se a la història. La mateixa historiografia reconeix que el temps és el gran concepte de la història. És molt coneguda la frase de l'historiador Fernand Braudel (1984): "L'historiador no s'evadeix mai del temps de la història: el temps s'adhereix al seu pensament com la terra a la pala del jardiner (...). Per a l'historiador tot comença i tot acaba amb el temps". Koselleck (1993) relaciona el temps històric amb la vida: "Qui pretén ferse una idea corrent del temps històric ha de prestar atenció a les arrugues d'un avi, a les cicatrius en què està present un destí de la vida passada".

La majoria d'anàlisis dels currículums europeus destaquen la importància del temps històric en l'ensenyament de la història a l'educació primària, com ja hem indicat en una altra publicació (SANTISTEBAN, PAGĖS, 2006), i també a Itàlia, on existeix una llarga tradició en aquest sentit (LANDI, 2006). I la majoria de propostes didàctiques més innovadores constaten la importància que l'aprenentatge del temps històric ha de servir per relacionar el passat amb el present i per poder construir el futur. Malgrat la importància del temps per a la història, aquesta ciència social no ha construït un model sobre el temps que pugui ser utilitzat per a l'ensenyament. Donada aquesta situació, la didàctica de la història ha de proposar un model que ens ajudi a saber què hem d'ensenyar i quina mena d'estructura conceptual sobre el temps han de construir els nens i nenes (PAGĖS i SANTISTEBAN, 1999; SANTISTEBAN, 1999; SANTISTEBAN, 2006). És a dir, si les teories constructivistes diuen que l'alumnat ha de construir els seus esquemes de coneixement, de quin model disposem per construir aquests esquemes?

Abans d'abordar el problema conceptual de l'aprenentatge del temps històric, s'ha de començar per parlar del temps com a llenguatge. La nostra experiència ens diu que, més enllà d'un vocabulari bàsic que s'adquireix als primers cursos de primària, el llenguatge s'ha d'enriquir a cada curs i ha d'estar present sempre com un instrument essencial per a la comprensió de la tempo- ralitat i de la pròpia història. Així, aquesta proposta s'explica a partir de dos grans blocs al voltant de l'ensenyament del temps: 1 ) el llenguatge i la temporalitat, i 2) l'estructura conceptual del temps històric.

\section{Què s'ha d'ensenyar del temps històric? El llenguat- ge i la temporalitat}

L'ensenyament de la història a l'escola primària ha de mostrar als nens i nenes que el temps està present $a$ totes les nostres accions o experiències de la vida quotidiana. El nostre llenguatge està farcit d'expressions o conceptes temporals, que fem servir per respondre: quan?, en quin moment?, ¿en quin ordre successiu? Els nens $i$ nenes necessiten el llenguatge temporal per parlar, escriure o explicar el seu món, per narrar les seves experiències o per indicar els seus desitjos de futur.

Al nostre llenguatge apareixen tot tipus de paraules, locucions o frases fetes relacionades amb la temporalitat, per matisar el nostre discurs o per ordenar els esdeveniments del nostre relat. El vocabulari temporal és imprescindible per realitzar narracions coherents i ben estructurades, per comunicar-nos amb altres persones. La riquesa de les narracions dels nens i nenes és proporcional a la l'amplitud del seu llenguatge temporal. En un altre lloc hem fet una proposta força completa del llenguatge temporal (SANTISTEBAN i PAGÈS, 2006).

Els contes que expliquem a l'escola són instruments importants per a l'aprenentatge dels conceptes temporals. Les activitats relacionades amb el temps de la nostra vida quotidiana ajuden també l'alumnat a comprendre la importància de la gestió del temps a la seva experiència social.

El llenguatge temporal és fonamental també a la narració històrica, ja que per a la construcció de la història necessitem ordenar els esdeveniments del passat. Així les persones anem construint tots els conceptes temporals. Aquests conceptes del temps històric són essencials per a l'aprenentatge de la història a l'educació primària.

\section{Quins conceptes han de construir els nens i nenes?} Els conceptes temporals

A més a més del llenguatge temporal, es necessita conèixer l'estructura conceptual del temps històric. El temps 


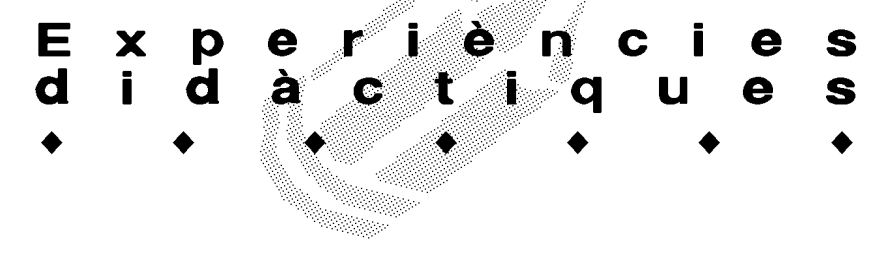

és un concepte de conceptes, i per comprendre els seus significats ens fem les següents preguntes: a) Què és la temporalitat humana? b) Com sabem que ha passat el temps? c) Qui té el poder sobre el temps?

\section{Què és la temporalitat humana?}

La temporalitat humana inclou tres conceptes: passat, present i futur. L'estudi del passat es relaciona amb la memòria i els records. La figura 1 recull les reflexions d'un nen de 10 anys sobre el concepte de la memòria aplicada a l'àmbit familiar.

\section{Com sabem que ha passat el temps?}

El temps passa perquè les coses canvien. El concepte de canvi està unit al de permanència. Les persones, per exemple, canviem contínuament des d'un punt de vista biològic, però sempre som la mateixa persona. Quan estudiem la història de la localitat indiquem els aspectes de canvi, de creixement urbà o de transformació del paisatge, però també les continuïtats en els carrers, els monuments o d'altres elements del patrimoni cultural i històric.

Els canvis tenen un ritme i una intensitat, s'acceleren o es fan més lents; de vegades parlem d'evolució i d'altres de revolució, de vegades parlem de creixement $i$ d'altres de desenvolupament. La visió positiva o negativa dels canvis es relaciona amb el progrés o amb el concepte de decadència. Tots aquests conceptes relacionats amb el canvi formen part de la interpretació que fa la història del passat.

A l'educació primària els temes diacrònics ajuden a comprendre millor els canvis: la història del vestit, l'evolució de l'habitatge o de l'escriptura (vegeu el quadre 1). L'estudi de temes al llarg del temps facilita la comparació entre el passat i el present. L'alumnat s'ha de plantejar com són, com eren i com seran en el futur els vestits, les cases o altres aspectes de la vida de les persones. A la següent activitat es pot observar com es treballa gràficament el canvi als primers cursos de primària.

\section{Qui té el poder sobre el temps?}

El poder sobre el temps el té qui sap organitzar-se.

Una de les maneres com les persones tenen el poder sobre el temps consisteix a saber dominar el nostre propi

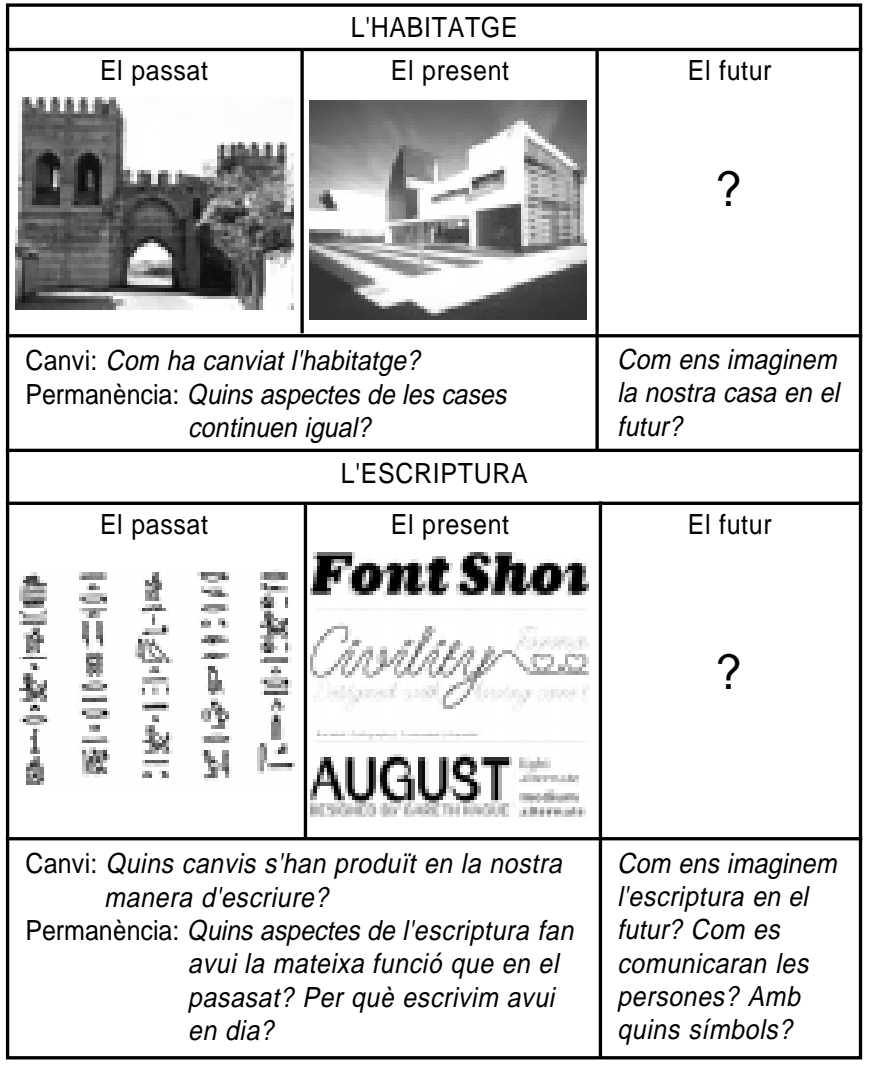

Quadre 1. Temes diacrònics que ajuden a comprendre millor els canvis temporals.

temps, el de la nostra vida diària, el temps de treball i el temps d'oci. Un exercici útil que es pot fer amb el nens i nenes de cicle mitjà d'educació primària és que representin el seu horari personal, i que després facin una proposta de millora de l'organització d'aquest horari. Aquest procés pot començar amb l'anàlisi de l'horari diari d'una nena com la que es pot veure a la figura 2. Les imatges estan desordenades i s'han d'ordenar amb l'ajuda del petit rellotge que acompanya cada dibuix.

El poder sobre el temps el té qui el sap mesurar.

Dominar la cronologia o els instruments de mesura del temps ha estat sempre una forma de domini social. Els calendaris o els rellotges han estat formes de con-

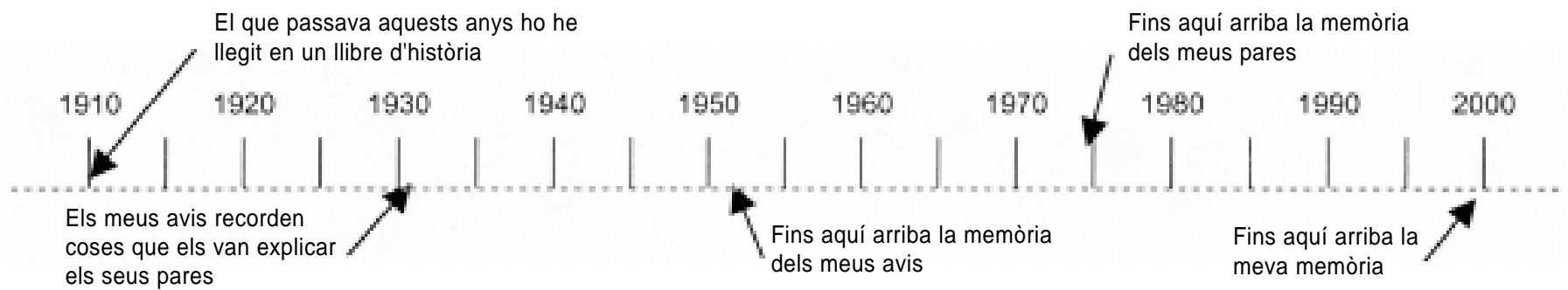

Figura 1. Reflexions d'un nen de 10 anys sobre el concepte de la memòria aplicada a l'àmbit familiar. 


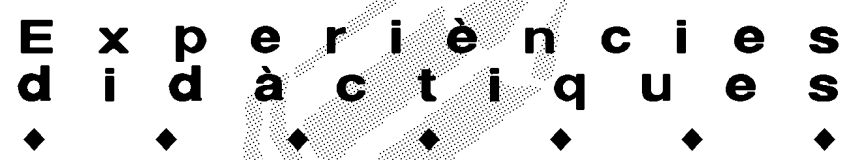

trolar el ritme de la vida de les persones. La cronologia correspon a la representació d'un temps objectiu, que necessitem per situar els esdeveniments històrics, així com per ordenar-los en una successió o, en alguns casos, per decidir la simultaneïtat dels fets.

Hem de diferenciar, però, la cronologia de la periodització històrica. La primera és objectiva, la segona és una representació qualitativa del temps, ja que els períodes històrics no són regulars. La cronologia es relaciona amb el rellotge i el calendari, però la periodització està lligada als canvis socials.
El poder sobre el temps el té qui sap perioditzar $i$ narrar la història.

En el cicle inicial de l'educació primària la periodització es pot relacionar, en primer lloc, amb les diferències que establim en el llenguatge per distingir entre el que és antic i el que és modern, com una primera aproximació a la classificació dels esdeveniments. Una altra manera de perioditzar és a partir de les generacions de la família: el que pertany al temps dels avis, dels pares, etc.

Per treballar la periodització històrica al cicle superior de l'educació primària proposem un mural on apareixen
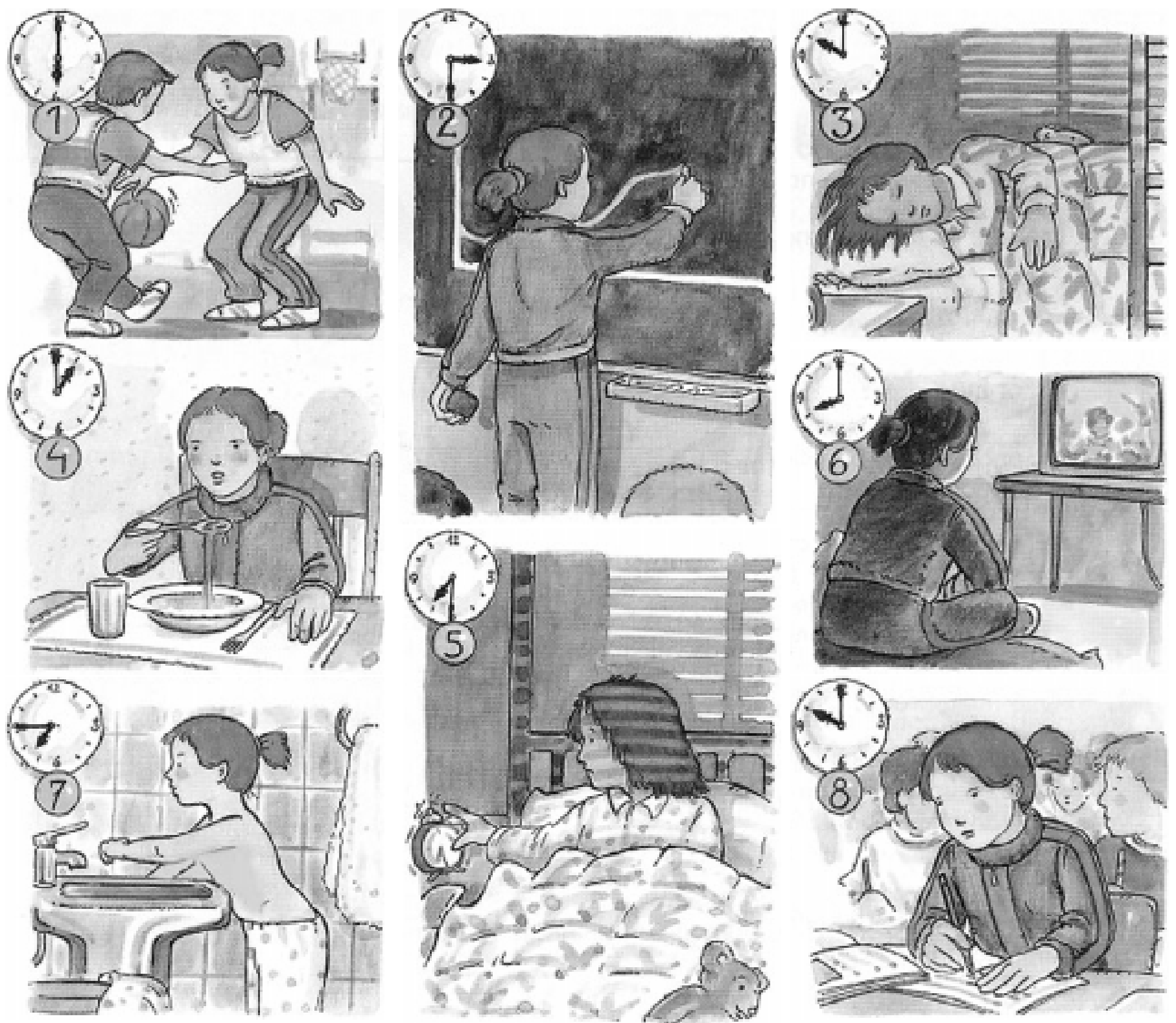

Figura 2. Dibuixos desordenats de l'organització de l'horari d'una nena de 8 anys. 


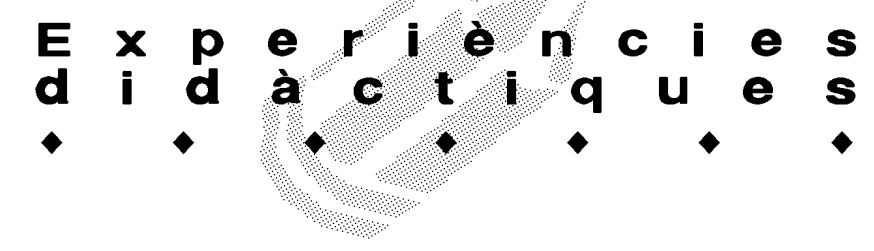

els períodes històrics, relacionats amb els diferents aspectes de la vida de les persones, de l'organització social i política, i de la cultura de les diverses èpoques. El mural pot ocupar una de les parets de la classe i cada quadrat o cada apartat ha de recollir un dibuix i una frase explicativa (vegeu el quadre 2). Una vegada acabat, la lectura horitzontal i vertical del mural ajuda a construir una mena de mapa temporal on situar els esdeveniments de la història, així com també a comprendre els processos de canvi.

El procés de treball implica la recerca d'informació en la biblioteca de la classe i la representació i síntesi de les idees. Seria bo que tots els grups treballessin aspectes diferents i totes les èpoques històriques. El treball autònom de l'alumnat permet al professorat ajudar a qui més ho necessiti, ja sigui a trobar la informació o a decidir què s'ha de representar en cada apartat. El procés complet de treball consta de 5 passos:

1. Per grups es reparteixen els quadres del mural, cada vegada d'una època històrica diferent fins a completar-les totes.

2. Cada grup treballa amb els llibres de la biblioteca de la classe i amb l'ajuda del professorat.

3. Dins de cada grup es fa un dibuix representatiu de l'apartat que els ha tocat i es decideix quina serà la frase explicativa que acompanyarà el dibuix; per exemple a l'apartat de l'alimentació en el paleolític: "Les persones s'alimentaven del que caçaven i pescaven, i de les plantes que recollien".

4. Cada vegada que un grup acaba un apartat, es colloca en el mural i comença un nou quadre, que podríem anomenar el mosaic de la història.

5. Quan el mural està acabat, cada nen i nena fa un informe sobre la lectura horitzontal de cada època històrica, així com de la lectura vertical de cada aspecte i la seva evolució en el temps.

Un mural semblant, però amb molts més apartats pot ser realitzat també cooperativament per més d'un centre educatiu, d'una ciutat o d'una comarca. Cada classe es pot responsabilitzar de diversos quadres del mural i un dia completar el mural en un acte públic. Cada quadre pot tenir la mida d'un full A-3, fet que dóna la possibilitat de formar un gran mosaic de la història, per exemple de la localitat on se situen les escoles. Sempre s'ha de tenir en compte que s'ha de preparar prèviament el mural amb quadrícules i els títols de les diverses èpoques històriques i dels diversos apartats.

El poder sobre el temps el té qui ajuda a construir el futur.

La construcció voluntària del futur, la intervenció social per millorar-lo són una altra manera de control i domini del temps. El futur s'ha de tractar des de la història a partir del coneixement que tenim del passat, a partir de la memòria històrica. El passat i el futur han de ser objecte d'ensenyament en l'educació democràtica de la ciutadania. Construir el futur requereix la reflexió sobre els diversos futurs que existeixen en el present, els futurs possibles, probables i desitjables.

\section{Referències bibliogràfiques}

BRAUDEL, F. La Historia y las Ciencias Sociales. Alianza Editorial. Madrid. 1984. Pàg. 97-99.

KOSELLECK, R. Futuro pasado. Para una semántica de los tiempos históricos. Edit. Paidós. Barcelona. 1993. Pàg. 13.

LANDI, L. Insegnare la storia ai bambini. Edit. Carocci. Roma. 2006.

PAGÈS, J. i SANTISTEBAN, A. La enseñanza del tiempo histórico: una propuesta para superar viejos problemas. En AAVV: Un currículum de Ciencias Sociales para el siglo XXI. Qué contenidos y para qué. Edit. Díada. Sevilla. 1999. Pàg. 187-207.

SANTISTEBAN, A. Aprender el tiempo histórico: deconstruir para reconstruir. «Historiar», 1 (1999) 141-150.

SANTISTEBAN, A. Une proposition conceptuelle pour la recherche et l'enseignement du temps historique. «Le Cartable de Clio», 6 (2006) 77-90.

SANTISTEBAN, A. i PAGÈS, J. La enseñanza de la historia en la educación primaria. Edit. Praxis. Barcelona. 2006.

\begin{tabular}{|l|l|l|l|l|l|l|}
\hline & Paisatge & Habitatge & Alimentació & $\begin{array}{c}\text { Tecnologia/ } \\
\text { Transports }\end{array}$ & Creences/Art & Organització/Poder \\
\hline Paleolític & & & & & & \\
\hline Neolític & & & & & & \\
\hline Ibers & & & & & & \\
\hline Romans & & & & & & \\
\hline Edat Mitjana & & & & & & \\
\hline Edat Moderna & & & & & & \\
\hline E. Contemporània (S. XIX) & & & & & & \\
\hline E. Contemporània (S. XX) & & & & & & \\
\hline futur & & & & & & \\
\hline
\end{tabular}

Quadre 2. Mural per treballar la periodització i els canvis històrics al cicle superior. El mural que hem anat realitzant estava estructurat de manera que cada quadre tenia la mida d'un full de paper DIN A-4. 